\title{
Direito à educação: da conquista ao reconhecimento
}

\author{
Right to education: from conquest to recognition
}

Derecho a la educación: de la conquista al reconocimiento

\section{Nilda Stecanela* \\ Caroline Caldas Lemons**}

\section{Resumo}

O texto apresenta uma tessitura conceitual-analítica do direito à educação e tem na Ciência Jurídica e na Teoria do Reconhecimento suas principais fundamentações teóricas. As reflexões sobre o direito à educação articulam aspectos que envolvem tanto a natureza do direito, sua validez e expressão legal quanto fatores atuantes para que esse seja reconhecido, de modo específico, no âmbito da educação escolar. À análise macro da temática acresce-se uma apresentação panorâmica do atual período histórico que demarca os trinta anos da conquista do direito à educação no Brasil como bem comum. De caráter bibliográfico, o estudo procurou aprofundar a discussão em torno do pressuposto que é preciso refletir acerca da natureza, validez e expressão legal do direito para que o direito à educação possa ser reconhecido no âmbito da educação escolar. O argumento desenvolvido considera que, embora a conquista jurídica seja importante, quando se trata de assegurar um direito, isoladamente é incapaz de garantir seu reconhecimento.

Palavras-chave: Direito à Educação. Direito subjetivo. Educação escolar. Reconhecimento de direitos.

\section{Abstract}

The text presents a conceptual-analytical framework of the right to education and has in Legal Science and in the Theory of Recognition its main theoretical foundations. Reflections on the right to education articulate aspects that involve both the nature of the law, its validity and legal expression as well as acting factors so that it is recognized, specifically, in the scope of school education. To the macro analysis of the theme is added a panoramic presentation of the current historical period that marks the thirty years of the conquest of the right to education in Brazil as a common good. With a bibliographic character, the study sought to deepen the discussion around the assumption that it is necessary to reflect on the nature, validity and legal expression of the right so that the right to education can be recognized within the scope of school education. The developed argument considers

Recebido em 26/03/2019 - Aprovado em 22/08/2019

http://dx.doi.org/10.5335/rep.v27i1.10580

Doutora em Educação pela Universidade Federal do Rio Grande do Sul (Ufrgs, Brasil) com estágio pós-doutoral em Educação, como bolsista Capes, no Institute of Education/University of London (EUA). É Pró-Reitora Acadêmica e docente do corpo permanente do Programa de Pós-Graduação em Educação da Universidade de Caxias do Sul (UCS, Brasil). É bolsista CNPq de Produtividade em Pesquisa. ORCID https://orcid.org/0000-0001-9946-0848. E-mail: nildastecanela@gmail.com

** Mestre em Educação e Doutoranda em Educação pelo Programa de Pós-Graduação em Educação da Universidade de Caxias do Sul (UCS, Brasil). Bolsista Capes/Prosuc. Professora da Educação Básica da Rede Municipal de Ensino de Caxias do Sul. ORCID https://orcid.org/0000-0003-4178-8036. E-mail: caroline.lemons35@gmail.com 
that, although legal achievement is important, when it comes to securing a right, it alone is incapable of guaranteeing its recognition.

Keywords: Right to education. Subjective right. Schooling. Recognition of rights.

\title{
Resumen
}

\begin{abstract}
El texto presenta una textura conceptual-analítica del derecho a la educación y tiene en la Ciencia Jurídica y la Teoría del Reconocimiento sus principales fundamentos teóricos. Las reflexiones sobre el derecho a la educación articulan aspectos que involucran tanto la naturaleza del derecho, su validez y expresión legal, como factores que actúan para su reconocimiento, específicamente, dentro del alcance de la educación escolar. Al análisis macro del tema se agrega una presentación panorámica del período histórico actual que marca los treinta años de la conquista del derecho a la educación en Brasil como un bien común. Con un carácter bibliográfico, el estudio buscó profundizar la discusión en torno al supuesto de que es necesario reflexionar sobre la naturaleza, validez y expresión legal del derecho para que el derecho a la educación pueda ser reconocido dentro del alcance de la educación escolar. El argumento desarrollado considera que si bien el logro legal es importante, cuando se trata de garantizar un derecho, por sí solo no puede garantizar su reconocimiento.
\end{abstract}

Palabras clave: Derecho a la educación. Derecho subjetivo. Educación escolar Reconocimiento de derechos.

\section{Contextualização inicial}

O que efetivamente significa ter direito à educação? Na dimensão escolar, sob quais condições ele pode ser reconhecido? Estas são algumas das questões mobilizadoras das reflexões almejadas neste texto, que trata das origens do direito subjetivo no qual se insere o direito à educação, de sua concepção na filosofia honnethiana e seu reconhecimento na dimensão da educação escolar.

A dimensão escolar da educação remete àquela que ocorre em uma instituição de ensino, pública ou privada, em que o ensino é planejado, os currículos previamente organizados e na qual são definidos espaços e tempos para a construção dos conhecimentos. Por ser um processo institucionalizado e específico, situado entre 0 primeiro ano de escolarização da criança até o final do Ensino Superior do adulto, pensar o direito à educação e também sua vivência no âmbito da Educação Básica implica ao menos três coisas: (a) refletir acerca da natureza do direito, sua validez e expressão legal, incluindo-se aí a diferença entre conquistá-lo e tê-lo reconhecido; (b) considerar os processos educacionais que envolvem a organização curricular, a formação de professores e a infraestrutura oferecida pelas escolas; e (c) problematizar as práticas ou modos de apropriação das políticas educacionais e dos recursos materiais e humanos disponíveis, especialmente por parte dos docentes.

Nesta escrita, propõe-se um aprofundamento da discussão em torno do primeiro pressuposto: o de que é preciso refletir acerca da natureza, validez e expres- 
são legal do direito para alargar o entendimento jurídico e, assim compreender os processos que envolvem o reconhecimento social do direito à educação no âmbito da educação escolar.

Para tanto, adotou-se como metodologia a pesquisa bibliográfica. Seu desenvolvimento deu-se a partir do aprofundamento conceitual-analítico do direito à educação em duas perspectivas complementares, a da Ciência Jurídica e a da Filosofia. Enquanto por intermédio da Ciência Jurídica, fundamentada em Bobbio (1992), foi possível definir o direito supracitado como um direito subjetivo para o qual se voltam obrigações morais; na perspectiva da Filosofia contemporânea, especificamente da Teoria do Reconhecimento discutida por Honneth (2003), foi possível ressaltar as questões práticas relacionadas ao reconhecimento do direito à educação no âmbito da educação escolar.

Diante dessas considerações, inicia-se refletindo sobre os pressupostos jurídicos e filosóficos dos direitos subjetivos; em seguida, apresenta-se a Teoria do Reconhecimento de Honneth (2003) em correlação com o direito à educação e, por fim, antecipando as conclusões, situa-se parte do caminho percorrido - entre a conquista e o reconhecimento - pelo direito à educação no Brasil.

\section{Direitos subjetivos}

Para qualquer realidade social em que exista o estabelecimento de relações entre os seres humanos presume-se a existência de regras ou garantias jurídicas. O ordenamento jurídico ou o Direito somente pode ser concebido em relação a uma coletividade, pois para essa coletividade se volta no sentido de salvaguardar e amparar a convivência social.

Toda regra de Direito visa a um valor, reconhecido dentre toda a pluralidade de valores que o ser humano representa. A partir desses valores são fundadas as normas jurídicas, com a pretensão de assegurar uma forma de vida compatível com a dignidade humana em termos de saúde, segurança, educação, habitação, alimentação etc.

Assim como a sociedade se renova, se reorganiza e se redefine, o ordenamento jurídico também não permanece estático. Seu movimento se opera a partir de demandas da própria sociedade e sua imperatividade está condicionada à diretriz expressada e considerada obrigatória pela coletividade.

A imperatividade do Direito está acompanhada de ações e exigências a serem cumpridas no meio social e, sendo assim, para cada norma anunciada há uma 
exigência de comportamento coletivo. Essa exigência opera como um dever ser, compreendendo tanto a obrigatoriedade quanto a possibilidade da não obediência, omissão ou violação da norma jurídica, para as quais resultam consequências ou sanções.

Nas palavras de Reale:

A imperatividade de uma norma ética, ou o seu dever ser não exclui, por conseguinte, mas antes pressupõe a liberdade daqueles a quem ela se destina. É essa correlação essencial entre o dever e a liberdade que caracteriza o mundo ético, que é o mundo do dever ser, distinto do mundo do ser, onde não há deveres a cumprir, mas previsões que têm de ser confirmadas para continuarem sendo válidas (REALE, 2002, p. 36, grifos do autor).

A existência da norma ou a previsão de sanções pelo seu descumprimento não basta para que ela possa vir a ser. Também é preciso que seja explicitado o que deve ser feito e de que maneira deve ser feito para que a norma seja aquilo que se propõe socialmente. A explicitação do como deve ser da norma jurídica visa esclarecer as normas éticas e as condutas esperadas. Ela também deve prever, havendo situações de desobediência, omissão ou violação, o uso da força via Judiciário, considerando que deve ser rigorosamente impedida toda e qualquer transgressão aos dispositivos que a coletividade considera indispensáveis à paz social.

As normas jurídicas não estão, portanto, destinadas a atender as pretensões individuais dos sujeitos, mas a coletividade, definindo juridicamente o que todos devem cumprir. Na acepção de Reale, o caráter heterônomo do Direito indica que:

A lei pode ser injusta e iníqua, mas, enquanto não for revogada, ou não cair em manifesto desuso, obriga e se impõe contra a nossa vontade, o que não impede que se deva procurar neutralizar ou atenuar os efeitos do "direito injusto", graças a processos de interpretação e aplicação que teremos a oportunidade de analisar (REALE, 2002, p. 49, grifos do autor).

Há que se destacar, entretanto, que o direito obriga, impõe, define - nem sempre de forma explícita - o que deve ser feito ou constituído. A falta de clareza em alguns aspectos, sobretudo no que diz respeito às lacunas ao enunciar ou expor as condições para o cumprimento da obrigação, abre espaço para diferentes interpretações.

Por obrigar ao que deve ser feito, nem sempre definindo os caminhos, a norma jurídica costuma valer-se de uma série de disposições complementares que traçam os rumos da ação e distribuem as competências e as atribuições para aqueles - órgãos públicos, por exemplo - que devem ordenar e pôr em funcionamento a obrigatoriedade prevista.

Mesmo visando finalidades comuns de uma coletividade e sendo o Direito legislado racional, heterônomo, de execução imediata por força de sua obrigatorieda- 
de (desde que não haja elementos condicionantes ou impedientes à sua executoriedade), alguns questionamentos emergem: Como assegurar que as relações sociais convirjam na direção do cumprimento da obrigatoriedade jurídica - e quiçá moral - das normas jurídicas? Como é possível saber o que cabe a cada um dos membros de uma comunidade?

De modo geral, cabe ao sujeito a faculdade de pretender ou fazer o que a norma lhe atribui, quer tratando-se de direito objetivo ou de direito subjetivo, porquanto complementares ${ }^{1}$. Reale faz o convite à compreensão do direito subjetivo como sendo "o interesse protegido que dá a alguém a possibilidade de agir. É, portanto, o interesse protegido enquanto atribui a alguém um poder de querer" (REALE, 2002, p. 255, grifos do autor).

O Direito subjetivo, portanto, constitui algo independente do fato de ser ou não reconhecido pelo Estado, mas para que seja garantido e protegido juridicamente é preciso observar se a vontade é possível ou potencial, uma vez que ele expressa aquilo que é devido em função de uma normativa jurídica ${ }^{2}$.

O Direito subjetivo está dentro de uma situação subjetiva que "é a possibilidade de ser, pretender ou fazer algo, de maneira garantida, nos limites atributivos das regras de direito". (REALE, 2002, p. 259, grifos do autor). Pode-se atestar que só existe direito subjetivo quando é possível pretender aquilo que é a exigibilidade do próprio direito objetivo, como explica Reale:

Assim sendo, a possibilidade de pretender ou fazer algo, - tal como se acha enunciada na regra de direito -, não tem alcance meramente descritivo ou puramente formal, mas representa, ao contrário, uma visão antecipada dos comportamentos efetivos, aos quais é conferida uma garantia. Isso corresponde, aliás, a um dos princípios já enunciados como sendo da essência do Direito: a sua realizabilidade garantida. Direito, não destinado a converter-se em momento de vida, é mera aparência de Direito. Norma de direito que enuncia numa possibilidade de fazer ou pretender algo, sem que jamais surja o momento de sua concretização na vida dos indivíduos e dos grupos como ação ou pretensão concretas, é uma contradição em termos. É próprio do Direito prever comportamentos prováveis, configurando, por antecipação, nos modelos jurídicos instaurados, aquilo que normalmente deverá ocorrer (REALE, 2002, p. 258, grifos do autor).

Conforme esclarece o autor, a pretensão está entre a norma - orientada para a realidade social - e a experiência, explicitando que se é possível pretender alguma coisa que está prevista na norma jurídica, deve ser possível exigir a garantia dessa pretensão.

Avançando na direção do entendimento histórico da questão dos direitos subjetivos, sabe-se que a primeira previsão e a redação desses direitos ocorreram a partir da segunda metade do século XVIII quando a França, por intermédio da De- 
claração dos Direitos do Homem e do Cidadão (1789), passou a cuidar dos direitos públicos dos seres humanos em uma perspectiva política.

Mais tarde, em 1948, com a Declaração Universal dos Direitos Humanos (DUDH) proclamada pela Assembleia Geral da Organização das Nações Unidas (ONU), esses direitos foram ampliados e complementados pelos direitos sociais dos indivíduos e dos povos. Naquele período histórico inaugural, tais Declarações conservaram um caráter jurídico-político, não se estendendo para além do estabelecimento de garantias das ações dos indivíduos no Estado ou contra ele e, apenas tardiamente, incorporaram perspectivas sociais e econômicas.

Logo após, contudo, muitas nações passaram a redigir seus ordenamentos jurídicos e a pautar suas políticas públicas na contemplação dessas previsões internacionais. Os desdobramentos da DUDH não convergiram para um único texto jurídico de alcance mundial, mas variaram de um país para outro e diferenciaram-se pela extensão das garantias previstas, bem como em seus processos de proteção.

No Brasil, os direitos públicos subjetivos fundamentais estão assegurados na Constituição Federal de 1988, no Título II, em especial nos capítulos I, II e IV, dentre os quais estão minuciosamente elencados os direitos e os deveres individuais e coletivos, os direitos sociais e políticos, da saúde, da previdência, da educação e da cultura.

Certamente o Direito, mesmo sendo lei, passa por interpretação lógica a fim de acompanhar as vicissitudes sociais num sentido compreensivo, correlacionando-as às fontes originais, aos outros dispositivos jurídicos e aos novos valores históricos, sem os quais seria inútil e prejudicial à coletividade. Nas palavras de Reale (2002) seria uma visão dupla (retrospectiva e prospectiva) da norma que resultaria na possibilidade de sua concretude, visto que seu significado inteligível é o que assegura que o caráter imperativo ou prescritivo da norma poderá ser aplicado.

Por ser atribuição daqueles que dela estão legalmente investidos, a aplicação da lei traz consigo o desafio da interpretação e da aplicabilidade em decorrência do princípio de sua realizabilidade ou efetividade. Para Reale, "a aplicação do Direito envolve a adequação de uma norma jurídica a um ou mais fatos particulares, o que põe o delicado problema de saber como se opera o confronto entre uma regra 'abstrata' e um 'fato concreto' [...]' (REALE, 2002, p. 300-301, grifos do autor).

Sendo possível, pelo próprio indicativo dos direitos subjetivos e, na medida em que a sociedade lhe confere reconhecimento, exigir de maneira garantida o que é de direito (objetivo), os direitos subjetivos tendem a alargar-se, mas também a tornarem-se mais complexos, pois, retomando o questionamento anterior: Como 
assegurar que as relações sociais convirjam na direção do cumprimento da obrigatoriedade jurídica - e quiçá moral - das normas jurídicas?

Bem, reconhecer os direitos públicos subjetivos, alicerçados sobre garantias eficazes, constitui o pilar característico do Estado Democrático de Direito, no qual a garantia efetiva e concreta não coexiste simplesmente como questão jurídica, mas vai além dessa esfera para vestir-se de questão fundamentalmente política.

Ainda com relação aos direitos subjetivos:

[...] podemos dizer que eles se impõem ao reconhecimento e ao respeito do Estado, sobretudo quando correspondem ao que temos denominado invariantes axiológicas, isto é, a valores universalmente proclamados e exigidos pela opinião pública como absolutamente essenciais ao destino do homem na face da Terra. Passa-se mesmo a falar em um Direito planetário consagrador de valores transnacionais e transestatais que conferem um novo fundamento aos direitos públicos subjetivos no plano do Direito Interno e do Direito Internacional. (REALE, 2002, p, 276, grifos do autor).

Por serem direitos públicos subjetivos eles exigem a parte do outro: seja ele indivíduo, coletivo ou Estado, uma vez que os deveres que correspondem a quaisquer direitos são partilhados pelas coletividades e pelas individualidades. Nesse sentido, para a realização do Estado Democrático de Direito é imperativo que o Estado assuma deveres e os faça corresponder à efetividade dos direitos públicos subjetivos.

A justiça, que "vale para que todos os valores valham" (REALE, 2002, p. 375, grifos do autor), não é gratuita nem acabada, mas é primordialmente intenção radical de garantir ao ser humano sua humanidade em uma convivência harmônica, plural e integral.

Reconhece-se, contudo, que a implantação das normas jurídicas de caráter social é bastante problemática porque algumas condições não dependem tão somente dos governantes (ainda que sejam políticas), mas dependem de ações individuais que as sustentem. Conforme afirma Bobbio, "o problema fundamental em relação aos direitos do homem, hoje, não é tanto o de justificá-los, mas o de protegê-los. Trata-se de um problema não filosófico, mas político" (1992, p. 24, grifos do autor) e é nesse ponto que muitas nações estão estagnadas.

A proteção e o reconhecimento são adiados dia após dia e relegados à vontade dos sujeitos que, muitas vezes, quando o fazem, fazem da forma como lhes apraz, apenas para o cumprimento de uma obrigação moral ou política. Por todas essas razões pode-se afirmar que somente boas intenções não resolvem o problema da sustentação dos direitos sociais e, em muitos desses casos, somente por intermédio da pressão da opinião pública ou mesmo da exigência social é que eles podem ser ao menos equilibrados. 


\section{Da conquista do direito à luta por reconhecimento}

Apesar de o reconhecimento não ser um tema novo nas discussões e teorias filosóficas, uma das reatualizações contemporâneas sobre o assunto o aborda a partir das deficiências deixadas por modelos teóricos tradicionais, acrescentando ao não reconhecimento o caráter propulsor para as mudanças sociais.

Em Luta por reconhecimento: a gramática moral dos conflitos sociais, Honneth (2003) explicita como os indivíduos se colocam nas sociedades contemporâneas a partir das experiências de não reconhecimento ${ }^{3}$ vivenciadas por eles. Embora $o$ assunto tenha sido tratado de forma muito ampla é possível inferir que o filósofo situa o conflito social no centro da discussão sobre o reconhecimento, pois para ele as possibilidades de emancipação dos sujeitos não estão apenas inseridas na própria realidade social, mas são dela projetadas.

Assim, de acordo com o autor, seriam três as etapas do reconhecimento recíproco $^{4}$ buscadas pelo sujeito e as quais ele muitas vezes vê-se privado: o amor, o direito e a estima social. $\mathrm{O}$ amor, encontrado na dedicação emotiva (tanto nas relações primárias de amizade, quanto nas de amor), quando bem atendido - por meio da satisfação mútua dos indivíduos - gera autoconfiança no sujeito, mas quando violado ou maltratado, afeta sua integridade física e sua personalidade. $\mathrm{O}$ direito, encontrado no respeito cognitivo presente nas relações jurídicas, quando bem atendido gera no indivíduo autorrespeito, mas, ao sentir-se dele desprovido, tem inteligência social atingida. A estima social, encontrada na solidariedade da comunidade de valores, gera autoestima no indivíduo, embora a degradação e a ofensa comprometam sua dignidade.

Como todas essas formas de reconhecimento são imprescindíveis para que o indivíduo desenvolva a autorrelação prática de que necessita para tornar-se membro de uma coletividade digna (autoconfiança, autorrespeito e autoestima), o desrespeito a qualquer uma concorre para impulsionar os conflitos sociais e, por intermédio desses, as mudanças sociais. Nas palavras de Salvadori:

A ruptura dessas autorrelações pelo desrespeito gera as lutas sociais. Portanto, quando não há um reconhecimento ou quando esse é falso, ocorre uma luta em que os indivíduos não reconhecidos almejam as relações intersubjetivas do reconhecimento. Toda luta por reconhecimento inicia por meio da experiência de desrespeito (SALVADORI, 2011, p. 191).

Ainda nessa perspectiva, Salvadori (2011) corrobora a teoria honnethiana, afirmando que as tensões sociais e as motivações morais dos conflitos advêm das três formas de reconhecimento malsucedidas ou desrespeitadas e que a superação 
dessas condições pelos indivíduos passa pelo reconhecimento de si e, posteriormente, pelo reconhecimento de si no outro.

O pressuposto de que o indivíduo, depois de reconhecer a si, passa a reconhecer-se no outro traduz o princípio da horizontalidade entre os seres humanos. Esse princípio faz com que pela luta social todos os direitos individuais fundamentais sejam ampliados na direção de uma medida maior de igualdade e para um número progressivo de membros da sociedade que passariam também a considerar - e a exigir - condições de seguridade iguais. Para Honneth:

[...] os confrontos práticos, que se seguem por conta da experiência do reconhecimento denegado ou do desrespeito, representam conflitos em torno da ampliação tanto do conteúdo material como do alcance social do status de uma pessoa de direito (HONNETH, 2003, p. 194, grifos do autor).

Concebendo que possuir direitos significa levantar pretensões que já se consideram socialmente justificadas, somente quando os direitos básicos universais não forem mais estendidos ao coletivo de maneira díspar a pessoa de direito terá o princípio de reconhecimento concretizado. Como explica o filósofo alemão, ainda que o indivíduo consiga tornar aceitas suas pretensões individuais por meio do direito, "é o caráter público que os direitos possuem [...] que lhes confere a força de possibilitar a constituição do autorrespeito" (HONNETH, 2003, p. 197).

O caráter público, referido por Honneth por meio da terceira forma de reconhecimento, a da estima social, implica na compreensão de duas questões. A primeira delas é que a estima social ou a solidariedade, como denomina Honneth, significa “[...] numa primeira aproximação, uma espécie de relação interativa em que os sujeitos tomam interesse reciprocamente por seus modos distintos de vida, já que eles se estimam entre si de maneira simétrica" (HONNETH, 2003, p. 209). É como se os sujeitos autônomos vissem em si mesmos, e nos outros, capacidades e propriedades e compartilhassem reciprocamente os valores que consideram significativos para a coletividade.

A segunda é que, embora essa forma de reconhecimento já tenha tido historicamente outros sentidos ${ }^{5}$, na modernidade e na discussão proposta, a estima social estaria relacionada de forma mais específica com a questão da dignidade e da integridade humanas, excluindo qualquer privilégio jurídico relacionado às qualidades morais outrora valorizadas, e se vincularia às finalidades sociais que a comunidade interpreta como sendo valiosas. Na contemporaneidade, portanto, ser reconhecido ou estimado socialmente exigiria a conquista da atenção pública. 
Assim sendo, a experiência de desrespeito, seja ela por violação, degradação, denegação, privação, negação, recusa, ofensa ou rebaixamento a qualquer uma das formas de reconhecimento afetaria a integridade psíquica do sujeito e provocaria nele a perda da autoconfiança. Os abalos psíquicos e as reações emocionais negativas, tais como a vergonha, a ira e o desprezo, provocadas pela percepção do não reconhecimento dos direitos, que para o sujeito é algo injustificado, acabariam por converter-se em propulsão para a luta por reconhecimento.

Isso significa que, ao sentir-se ferido em suas pretensões e tomado por sentimentos negativos, o indivíduo problematizaria suas expectativas, ou seja, diante do insucesso e tomado por sentimentos de culpa e de indignação moral - em geral, paralisantes -, ele tomaria consciência e seria impulsionado para a ação. Esse processo assinala que as experiências individuais iniciais de desrespeito se flexibilizariam e seriam superadas pela constituição de uma identidade coletiva.

Honneth (2003) explica que da experiência inicialmente particularizada do indivíduo emergiria a compreensão de que ela é sentida e vivida potencialmente por muitos outros sujeitos. Diante dessa descoberta, o indivíduo passaria a pensar na luta pelo reconhecimento jurídico e social não mais como uma questão de interesse individual, mas coletivo.

Tendo sido esclarecido que (a) o impulso do indivíduo para a luta por reconhecimento é decorrente de sua identidade lesada ou destruída pela infração da expectativa de ser estimado socialmente, (b) que a negação experienciada o aproxima do coletivo e que (c) é no coletivo que ele encontra as condições para lutar pela autorrealização, adentra-se na análise dos caminhos percorridos pelo direito à educação no Brasil, no âmbito da educação escolar.

Antecipa-se que a luta pelo reconhecimento jurídico do direito à educação no Brasil, alcançado por intermédio de governos representativos, movimentos políticos e pressões sociais, ainda demanda movimentos. Contudo, é para o reconhecimento social que os esforços se voltam neste momento, pois sua concretude é mais difícil do que a jurídica, exigindo investimentos por parte de quem o pode legitimar na(s) prática $(\mathrm{s})$.

\section{Direito à educação no Brasil}

$\mathrm{Na}$ perspectiva honnethiana, as experiências morais - por sua alta carga emotiva e cognitiva - são as propulsoras das lutas sociais e dos movimentos coletivos pelo reconhecimento dos direitos. A título de exemplo e também de análise 
tem-se o caso do direito à educação no Brasil em que da negação inicial à violação atual nasceu o impulso para a luta pelo reconhecimento, tanto jurídico quanto prático.

Embora socialmente justificada durante vários séculos, a tratativa jurídica e a regulamentação do assunto somente ocorreu com a promulgação da Constituição Federal de 1988. Sua inserção no texto da Carta Magna decorreu tanto da pressão popular exercida pelos movimentos sociais quanto da movimentação dos representantes políticos do país. Essa semântica coletiva que conduziu os processos de socialização na direção da garantia da educação escolar abriu espaço para a alfabetização da população e também para o exercício de outros direitos como o direito ao voto, à saúde e a assistência social, a ampliação do conhecimento cultural e ao acompanhamento dos progressos técnicos e científicos contemporâneos.

A extensão progressiva do acesso à escola, que pode ser acompanhada (a) nos índices de matrícula dos estudantes em idade escolar nas instituições públicas e particulares de ensino do país nos últimos anos, bem como por meio (b) do fluxo de entrada e saída dos estudantes do Ensino Fundamental para o Ensino Médio, (c) da proporção entre as taxas de reprovação, abandono e aprovação e (d) da defasagem idade/escolaridade, relacionados nas Tabelas 1 a 4, permite que se fale em uma quase universalização da Educação Básica.

Nas tabelas a seguir, é possível observar o total de matrículas no Ensino Fundamental em 2016 e no Ensino Médio nos anos de 2016 e 2017.

\begin{tabular}{|c|c|}
\hline & 2016 \\
\hline $1 \stackrel{\circ}{\text { ano }}$ & 2.866.919 \\
\hline $2^{\circ}$ ano & 2.987 .495 \\
\hline 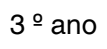 & 3.293 .034 \\
\hline $4^{\circ}$ ano & 3.179 .597 \\
\hline $5^{\circ}$ ano & 3.114 .994 \\
\hline $6 \stackrel{\circ}{\text { ano }}$ & 3.421 .168 \\
\hline 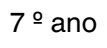 & 3.182 .329 \\
\hline 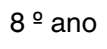 & 2.831 .086 \\
\hline $9 \stackrel{\circ}{\text { ano }}$ & 2.814 .856 \\
\hline
\end{tabular}


Tabela 2 - Total de matrículas no ensino médio

\begin{tabular}{|c|c|c|}
\hline & 2016 & 2017 \\
\hline $1^{\circ}$ ano & 2.986 .788 & 2.901 .789 \\
\hline 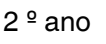 & 2.436 .965 & 2.362 .706 \\
\hline 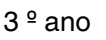 & 2.151 .914 & 2.080 .294 \\
\hline
\end{tabular}

Pelas Tabelas 1 e 2 , percebe-se que, entre o $1^{\circ}$ e o $3^{\circ}$ ano, o número total de matrículas no Ensino Fundamental sofreu acréscimos consideráveis; tendo na sequência, na passagem do $3^{\circ}$ para o $4^{\circ}$ ano e do $4^{\circ}$ para o $5^{\circ}$ ano, um decréscimo e, do $5^{\circ}$ para o $6^{\circ}$ ano, novo crescimento. A partir daí os dados nacionais demonstram um decréscimo progressivo em direção ao 9aa. Tais acréscimos e/ou decréscimos na passagem de um ano para outro indicam pontos de retenção e/ou avanço de estudantes e merecem discussão mais aprofundada, visto que entendê-los extrapola a dimensão da educação escolar.

Na comparação sobre o total de matrículas entre os níveis de ensino, observa-se que o total de matrículas no $1^{\circ}$ ano do Ensino Médio em 2017 (2.901.789) foi superior em $3 \%$ ao total de matrículas de estudantes no $9^{\circ}$ ano do Ensino Fundamental no ano de 2016 (2.814.856), indicando uma possível matrícula de estudantes repetentes no $1^{\circ}$ ano do Ensino Médio.

Outra observação que merece atenção diz respeito ao total de estudantes matriculados e concluintes do Ensino Médio, pois de um total de 2.436.965 estudantes matriculados no $2^{\circ}$ ano em 2016, que deveriam ter concluído esta etapa de ensino em 2017, somente 2.080.294 haviam se matriculado para o $3^{\circ}$ ano do Ensino Médio. Isso representa apenas um pouco mais de $85 \%$; sem considerar aqueles que não frequentaram ou não concluíram o ano letivo.

$\mathrm{Na}$ tabela a seguir, outras questões convidam a reflexão. Em todas as etapas da Educação Básica, a situação de reprovação ou abandono tem melhorado nacionalmente. Entretanto, somadas, ainda representavam, em 2016, o porcentual de 6,8\% nos anos iniciais, 14,5\% nos anos finais e 18,6\% no Ensino Médio (em 2015 eram respectivamente $6,8 \%, 14,3 \%$ e $18,4 \%$; e em $2014,7,3 \%, 15,2 \%$ e $19,8 \%$ ). 
Tabela 3 - Proporção de estudantes com reprovação, abandono ou aprovação

\begin{tabular}{l|c|c|c|c|c|c|c|c|c}
\cline { 2 - 10 } & \multicolumn{3}{c|}{2014} & \multicolumn{3}{c|}{2015} & \multicolumn{3}{c}{2016} \\
\hline Anos iniciais & $6,2 \%$ & $1,1 \%$ & $92,7 \%$ & $5,8 \%$ & $1,0 \%$ & $93,2 \%$ & $5,9 \%$ & $0,9 \%$ & $93,2 \%$ \\
Anos finais & $11,7 \%$ & $3,5 \%$ & $84,8 \%$ & $11,1 \%$ & $3,2 \%$ & $85,7 \%$ & $11,4 \%$ & $3,1 \%$ & $85,5 \%$ \\
Ensino médio & $12,2 \%$ & $7,6 \%$ & $80,2 \%$ & $11,6 \%$ & $6,8 \%$ & $81,6 \%$ & $12,0 \%$ & $6,6 \%$ & $81,5 \%$ \\
\hline
\end{tabular}

Fonte: QEdu (2019)

Legenda: R (Reprovação); Ab (Abandono); Ap (Aprovação).

Ainda que as últimas três décadas tenham sido marcadas por avanços nos índices de matrícula na Educação Básica, observam-se enormes proporções de estudantes com defasagem idade/escolaridade que precisam ser superadas. Analisando as informações na tabela a seguir - em que são dispostos os dados referentes a proporção de estudantes com defasagem idade/ano de dois anos ou mais -, fazendo um retrospecto um pouco mais distanciado do momento atual e relacionando-o a dados mais recentes, pode-se dizer que há uma população discente afastada dos ideais educacionais de idade/escolaridade.

Tabela 4 - Proporção de estudantes com defasagem idade/ano de dois anos ou mais

\begin{tabular}{l|l|l|l}
\cline { 2 - 4 } & 2008 & 2014 & 2016 \\
\hline Anos iniciais & $18 \%$ & $14 \%$ & $12 \%$ \\
Anos finais & $27 \%$ & $27 \%$ & $26 \%$ \\
Ensino médio & $24 \%$ & $28 \%$ & $28 \%$ \\
\hline
\end{tabular}

Fonte: QEdu (2019).

Em nível nacional, de 2008 para 2016 o porcentual de estudantes com esse descompasso nos anos iniciais do Ensino Fundamental diminuiu 6\%, sendo 1\% nos anos finais e 4\% no Ensino Médio. Reunidas e analisadas essas questões, cabe ainda trazer alguns números para observar a educação escolar no país. Em 2010, segundo o Instituto Brasileiro de Geografia e Estatística (IBGE), a partir dos dados coletados no Censo Demográfico (decenal), havia mais de 2,8 milhões de crianças e adolescentes em idade escolar fora da escola ${ }^{6}$. Detendo-se sobre os números líquidos, torna-se mais palpável perceber que não ter essa expressiva quantidade de crianças matriculadas e frequentando adequadamente a escola, no período determinado para isto, é mais desafiador do que se pode pensar em um primeiro momento. 
Apesar de os números de matrículas serem mais animadores do que os que foram verificados em décadas anteriores, não se pode falar em universalização da Educação Básica, visto que não se conseguiu ainda atingir a totalidade da população de crianças e jovens em idade escolar. $\mathrm{O}$ índice de $92 \%$ sinaliza que o acesso e a permanência, que, por vezes, parecem resolvidos, ainda demandam esforços políticos, de gestores escolares e de professores, pois há indícios de que estejam relacionados a fatores endógenos e exógenos que adentram a escola e o sistema escolar.

As situações de crianças fora da escola decorrem de inúmeras questões (pobreza, violência, gravidez, trabalho etc.) e não se tem aqui a pretensão de determiná-las. Destaca-se, entretanto, a grande dificuldade que é assegurar o acesso a todos, a permanência, a superação da defasagem idade/escolaridade e, especialmente, a aprendizagem $^{7}$, disputada com os porcentuais de reprovação e abandono.

Outro dado importante e que merece ser observado diz respeito ao índice de analfabetismo da população com 15 anos ou mais, divulgado pelo IBGE em maio de 2018, uma vez que caiu de 7,2\% em 2016 para 7,0\% em 2017, longe dos 6,5\% estipulados no Plano Nacional de Educação $\left(\mathrm{PNE}^{8}\right)$ para o ano de 2015 e, mais longe ainda de atingir a meta estabelecida pelo PNE de zerar os mais de 11 milhões de pessoas que não sabem ler nem escrever, até o ano de 2024.

Certamente, o atendimento do direito à educação inclui o aumento de matrículas, mas acompanha várias preocupações em relação à aprendizagem, a qualidade do ensino e as experiências proporcionadas aos estudantes. Ter direito à educação não se restringe a possibilidade de acessar e frequentar a escola. Ocorre que o direito à educação é histórico, nascido em determinado contexto e estendido gradualmente à medida que se tornou requerido. Trinta anos atrás, o desejo maior era pela conquista, ou seja, pelo reconhecimento jurídico. Hoje, contudo, a exigência é por reconhecimento social e por novas formas de proteção.

As emergências contemporâneas caminham em direção ao alargamento do direito e da discriminação das obrigações públicas e individuais, pois uma vez satisfeita a conquista jurídica (ainda que não na totalidade), os envolvidos sentem a necessidade de lutar por padrões ampliados de reconhecimento. Para consegui-los, engajam-se em ações políticas e deixam para trás a situação passiva ou acomodada em que se encontravam. Emerge, assim, uma autorrelação nova e positiva de si mesmo que restitui ao indivíduo, ao menos em parte, o autorrespeito perdido. Como pondera Honneth: 
[...] sentimentos de desrespeito formam o cerne de experiências morais, inseridas na estrutura das interações sociais porque os sujeitos humanos se deparam com expectativas de reconhecimento às quais se ligam as condições de sua integridade psíquica; esses sentimentos de injustiça podem levar a ações coletivas, na medida em que são experienciadas por um círculo inteiro de sujeitos como típicos da própria situação social (HONNETH, 2003, p. 260).

O não reconhecimento, além de privar os atingidos daquilo que era uma pretensão legítima, os deixa tomados por um sentimento de inferioridade de valor. É importante lembrar que para autorrealizar-se o indivíduo depende do reconhecimento de si como um membro único e insubstituível de uma coletividade, com capacidade de contribuir para a manutenção e reprodução da vida social de forma positiva.

Assim, para o reconhecimento moral dos direitos, não basta que apenas se considere o outro com o mesmo respeito que tem para com si mesmo, mas que não se ofereça a ele um reconhecimento distorcido ou limitado. Para Honneth, a contingência recorrente da não consideração de que as condições que um sujeito tem para alcançar sua autorrealização são parte do reconhecimento, permite afirmar que "[...] a experiência da privação de direitos se mede não somente pelo grau de universalização, mas também pelo alcance material dos direitos institucionalmente garantidos" (HONNETH, 2003, p. 217).

Essa perspectiva é suficiente para afirmar que há uma tendência a certa naturalização do direito, ou seja, depois das pretensões individuais tornarem-se coletivas, da conquista jurídica ter sido alcançada por meio da luta, que institui legalmente o exercício da cidadania, há um processo de estagnação. Para sair desse estado e assegurar a manutenção do direito, novas intervenções são requeridas.

Como todo direito induz a uma obrigação moral correspondente, na medida em que, ao saber-se sujeito de direitos, o indivíduo entende que tem obrigação para com o outro na mesma proporção que tem para consigo, há o encaminhamento para a luta por condições concretas de realização que permita a todos saber mais sobre as condições e as possibilidades da autorrealização.

A intensa defasagem no campo dos direitos sociais dá-se em razão da dificuldade de assegurar às condições intersubjetivas (atendimento do amor, do direito e da estima social), a incorporação de elementos materiais adjacentes (materialidade necessária para que as capacidades e habilidades sejam externadas), sem deixar de contemplar as condições históricas.

Observa-se finalmente que o direito não pode limitar-se à existência das normas jurídicas. Para o exercício democrático do Direito, é preciso que se coadunem o aperfeiçoamento jurídico e as possibilidades de sua aplicação, ou seja, considerar mais as condições particulares dos indivíduos, sem perder de vista o conteúdo universalista. 
Por sorte - ou por luta -, nas sociedades desenvolvidas, as condições da autorrealização vêm sendo ampliadas. Experiências individuais ou coletivas de negação, desrespeito ou violação de direitos converteram-se em impulso para luta e organização de movimentos políticos. Contudo, seu cumprimento demanda tempo, paciência e, acima de tudo, mudança cultural que conduza a uma ampliação essencial das relações de reconhecimento.

É difícil apontar o caminho mais rápido, eficaz ou seguro de reconhecimento e realização dos direitos humanos, especialmente quando se trata de proteger um direito subjetivo como é o direito à educação, mas é possível afirmar que as condições de exequibilidade dos direitos proclamados é a meta a ser buscada.

\section{Considerações finais}

A opção por estabelecer aproximações entre Honneth (2003), a Ciência Jurídica e o campo da Educação parte da compreensão de que os conflitos sociais oriundos do desrespeito às formas de reconhecimento podem explicar a evolução ou o desenvolvimento moral das sociedades. $\mathrm{O}$ desejo por mudanças educacionais precisa estar acompanhado tanto da segunda, quanto da terceira forma de reconhecimento, pois à medida que se avança na jurisprudência, novas relações práticas são reivindicadas.

Diante da constatação de que, mesmo havendo uma justificada garantia jurídica para o direito à educação, ele não está dado, entende-se que a legitimidade precisa ser construída por meio de processos de luta resultantes de interações entre sujeitos. Conclui-se que é pressuposto da garantia do direito à educação a luta, passando pela conquista, para o exercício da cidadania e a requisição de intervenção para a sua manutenção.

O direito à educação, como um direito subjetivo que se legitima quando as concessões legais e as relações intersubjetivas se transformam em ações práticas, requer (muita) luta. Estendê-lo, garanti-lo e legitimá-lo sob o princípio da igualdade universal independente das disposições econômicas, ainda é miragem. A propósito, diante da imputabilidade moral referida e de novas situações sociais conflitantes em que o sujeito se sinta lesado, cabe a ele a ampliação de suas pretensões jurídicas e a luta pelo reconhecimento das propriedades universais das quais se considera digno.

Consoante com os dizeres de Bobbio de que "[...] uma coisa é um direito; outra, a promessa de um direito futuro. Uma coisa é um direito atual; outra, um direito potencial" (1992, p. 83) e, observando a história das políticas educacionais 
no Brasil, é possível afirmar que hoje o direito à educação ainda está em processo de aproximação entre o plano da conquista jurídica e o da legitimidade universal, horizontal e inalienável.

É mais um vir a ser do que realmente o é, pois embora não dependa exclusivamente das políticas públicas para existir, ainda requer, para a sua legitimidade e manutenção, a intervenção do Estado e, no mesmo patamar de importância, dos atores da educação, pois é na intimidade da sala de aula que as compreensões de educação são postas em prática.

\section{Notas}

1 Ao direito objetivo corresponde a norma ou lei, tal como está redigida. Já ao direito subjetivo, pode-se dizer genericamente, corresponde à vontade e ao interesse expressados e juridicamente protegidos.

2 Um direito é subjetivo na medida em que vai ao encontro do sujeito para quem o direito objetivo se realiza, o que explica não ser possível que haja direito subjetivo sem que haja a regra jurídica.

3 Ainda que não esgote a questão, ao tecer sua versão da Teoria Crítica iniciada por Hegel, Honneth (2003) explora detalhadamente as três formas de reconhecimento e o conceito de luta, trazendo para o centro do debate filosófico a estrutura das relações sociais de reconhecimento. Busca na Psicologia Social essa atualização para afirmar que os conflitos sociais são consequências do não reconhecimento a qualquer uma das formas de reconhecimento explicadas na sequência do texto.

4 É importante considerar que qualquer uma das formas de reconhecimento exige o reconhecimento intersubjetivo e a complementaridade, uma vez que não apenas inexiste entre elas graduação, quanto o desrespeito a uma delas, qualquer que seja, impede a autorrealização do sujeito. A autorrealização mencionada corresponde: a) no amor, à autoconfiança; b) no direito, ao autorrespeito e c) na estima social, à autoestima.

5 Ser reconhecido no sentido da estima social teve por longo tempo (embora ainda presente em algumas sociedades) o sentido de honra, ou seja, vinculado as expectativas socioeconômicas e de prestígio social, a capacidade individual ou a reputação social a partir daquilo que o indivíduo realizava ou que era capaz em função dos objetivos da sociedade.

6 Os dados fazem referência à faixa etária que vai dos seis aos dezessete anos de idade e não contempla as crianças de quatro e cinco anos de idade, considerando que a obrigatoriedade de matrícula para crianças nessa faixa etária somente ocorreu em 2016, por força da Lei no $12.796 / 2013$.

7 Neste momento não há condições de aprofundar tais questões, mas considera-se importante sinalizar para uma problematização mais cuidadosa em torno das indagações que se referem ao acesso, a frequência, sucesso ou insucesso escolar; do ponto de vista de como estão relacionadas às políticas educacionais que por meio das mantenedoras - municipais e estaduais - adentram as escolas de Educação Básica do país.

8 É possível conhecer as metas do Plano Nacional de Educação (2014-2024), lei no ${ }^{13.005 / 2014}$, acessando o site indicado nas referências.

\section{Referências}

BOBBIO, Norberto. A era dos direitos. 11. ed. Rio de Janeiro: Elsevier, 1992.

BRASIL, Lei 13.005, de 25 de junho de 2014. Aprova o Plano Nacional de Educação - PNE e dá outras providências. Disponível em: https://presrepublica.jusbrasil.com.br/legislacao/125099097/lei-13005-14. Acesso em: 21 mar. 2019. 
QEDU. Matrículas no Ensino Fundamental 2016. Disponível em: https://www.qedu.org.br/brasil/censo-escolar. Acesso em: 10 jan. 2019.

QEDU. Matrículas no Ensino Médio 2016-2017. Disponível em: https://www.qedu.org.br/brasil/ censo-escolar. Acesso em: 10 jan. 2019.

QEDU. Taxas de Rendimento 2014-2015-2016. Disponível em: https://www.qedu.org.br/brasil/ taxas-rendimento/todas-as-redes/rural-e-urbana. Acesso em: 10 jan. 2019.

QEDU. Distorção Idade-Série 2008-2014-2016. Disponível em: https://www.qedu.org.br/brasil/ distorcao-idade-serie. Acesso em: 10 jan. 2019.

HONNETH, Axel. Luta por reconhecimento: a gramática moral dos conflitos sociais. São Paulo: Ed. 34, 2003.

REALE, Miguel. Lições preliminares de direito. 27 ed. São Paulo: Saraiva, 2002.

SALVADORI, Mateus. Resenha: HONNETH, Axel. Luta por reconhecimento: a gramática moral dos conflitos sociais. Tradução de Luiz Repa. São Paulo: Ed. 34. Conjectura, Caxias do Sul, RS, v. 16, n. 1, p. 189-192, jan./abr. 2011.

STECANELA, Nilda. Jovens e cotidiano: trânsitos pelas culturas juvenis e pela escola da vida. Caxias do Sul: Educs, 2010. 